\title{
KỸ NĂNG ĐIỀU CHỈNH CẢM XÚC ÂM TÍNH TRONG GIAO TIẾP VỚI TRẺ CỦA GIÁO VIÊN MÀM NON
}

\author{
PHAN THI TỐ OANH ${ }^{1}$, NGUYẼ̃N THI HOÀNG YÊN ${ }^{2}$ \\ ${ }^{1}$ Khoa Thuơng Mại và Du Lịch, Truờng Đại học Công nghiệp Thành phố Hồ Chí Minh; \\ ${ }^{2}$ Truoờng mẫu giáo Tuổi Hồng, Quận Tân Phú, Thành phố Hồ Chi Minh; \\ phanthitooanh@iuh.edu.vn
}

Tóm tắt. Kỹ năng điều chỉnh cảm xúc âm tính trong giao tiếp với trẻ của giáo viên mầm non là khả năng nhận ra những cảm xúc âm tính không phù hợp, từ đó lựa chọn và thực hiện các cách điều chỉnh hiệu quả nhằm giảm bớt hoặc thay đổi các cảm xúc âm tính của bản thân giáo viên trong giao tiếp giữa họ với trẻ. Kết quả từ việc khảo sát trên 254 giáo viên mầm non tại 10 trường mầm non trên địa bàn Quận Tân Phú, Thành phố Hồ Chí Minh năm 2019, bao gồm cả trường công lập và ngoài công lập cho thấy: Mức độ kỹ năng điều chỉnh cảm xúc âm tính trong giao tiếp với trẻ của giáo viên mầm non hiện nay là mức trung bình. Chúng tôi đề xuất 4 biện pháp nhằm hô̂ trợ giáo viên mầm non rèn luyện nâng cao kỹ năng này. Đó là: Trang bị tri thức cho giáo viên mầm non về kỹ năng điều chỉnh cảm xúc âm tính trong giao tiếp với trẻ; Hướng dẫn giáo viên mầm non rèn luyện kỹ năng nhận ra các cảm xúc âm tính không phù hợp với hoàn cảnh hiện tại; Hướng dẫn giáo viên mầm non rèn luyện kỹ năng thay đổi các cảm xúc âm tính; Hướng dẫn giáo viên mầm non đánh giá và hiệu chỉnh kỹ năng điều chỉnh cảm xúc âm tính trong giao tiếp với trẻ.

Từ khóa: Kỹ năng, kỹ năng điều chỉnh cảm xúc, cảm xúc âm tính, giáo viên mầm non.

\section{SKILLS ADJUST NEGATIVE EMOTIONS IN COMMUNICATING WITH CHILDREN OF PRE-SCHOOL TEACHERS}

Summary. Preschool teachers' skill of adjusting negative emotions in communicating with children can be described as the ability to identify inappropriate negative emotions, thereby select and make effective modifications to ease or change these emotions in interacting with children. The results from a research of over 254 preschool teachers at 10 preschools consisting of public and non-public ones in Tan Phu District, Ho Chi Minh City in 2019 proved that the extent of the skill related to adjusting negative emotions of preschool teachers in communicating with children was average. Therefore, four measures are proposed to support preschool teachers in improving this skill including to equip teachers sufficient knowledge on the skill of adjusting negative emotions, to instruct them practice the skill of identifying inappropriate negative emotions for the current circumstances, to guide them practice the skill of modifying these negative emotions, and to assist them in evaluating and correcting the skill of adjusting negative emotions in interacting with children

Key works. skill, skill of adjusting emotions, negative emotions, preschool teachers

\section{1. ĐẶT VẤN ĐỀ}

Sự hình thành và phát triển nhân cách con người là quá trình lâu dài và phụ thuộc vào nhiều yếu tố, trong đó, yếu tố giáo dục giữ vai trò chủ đạo[1]. Trường mầm non với mục tiêu "giúp trẻ em phát triến về thể chất, tình cảm, trí tuệ, thẩm mỹ, hình thành nhũng yếu tố đầu tiên của nhân cách, chuẩn bị cho trẻ em vào học lớp $m o \hat{t} t$ '"[2] là một trong những nền tảng căn bản ban đầu để xây dựng nên những con người phát triển toàn diện. Để thực hiện được mục tiêu này, người GVMN trước hết phải có trình độ về chuyên môn, nghiệp vụ. Bên cạnh đó, việc rèn luyện các phẩm chất đạo đạo đức cũng như các kỹ năng chăm sóc giáo dục trẻ cũng vô cùng cần thiết. Một trong những kỹ năng có ảnh hưởng sâu sắc đến mọi hoạt động trong quá trình thực hành nghề của GVMN là kỹ năng điều chỉnh CXÂT trong giao tiếp với trẻ.

\section{GIẢI QUYẾT VẤN ĐỀ}

\subsection{Một vài vấn đề lí luận}

Theo Từ điển Tâm lý học của tác giả Vũ Dũng, kỹ năng là "năng lực vận dụng có kết quả những tri thức về phương thức hành động đã được chủ thể lĩnh hội để thực hiện những nhiệm vụ tương ứng. Ở mức độ kỹ 
năng, công việc được hoàn thành trong điều kiện hoàn cảnh không thay đổi, chất lượng chưa cao, thao tác chưa thuần thục và còn phải tập trung chú ý căng thẳng. Kỹ năng được hình thành qua luyện tập". (Vũ Dũng (Chủ biên), 2000, tr.131)

Từ điển Tiếng Việt của Hoàng Phê thì cho rằng kỹ năng là "khả năng vận dụng những kiến thức thu nhận được trong một lĩnh vực nào đó vào thực tế” (Hoàng Phê (chủ biên), 2003, tr.520).

Tác giả Huỳnh Văn Sơn và các cộng sự định nghĩa "kỹ năng là khả năng thực hiện có kết quả một hành động nào đó bằng cách vận dụng những tri thức, những kinh nghiệm đã có để hành động phù hợp với những điều kiện cho phép. Kỹ năng không chỉ đơn thuần về mặt kỹ thuật của hành động, mà còn biểu hiện năng lực của con người” (Huỳnh Văn Sơn (Chủ biên) et al., 2012, tr.19).

Tổng hợp các khái niệm và các nhận định trên, chúng tôi cho rằng "Kỹ năng là khả năng vận dụng các tri thức và kinh nghiệm của cá nhân để thực hiện có kết quả một hoạt động bất kỳ trong cuộc sống”"

Kỹ năng điều chỉnh cảm xúc âm tính (CXÂT) là một lĩnh vực nghiên cứu còn khá mới mẻ, chưa có nhiều công trình nghiên cứu, cả trong nước lẫn ở nước ngoài. Hầu hết các công trình liên quan đến lĩnh vực này đều nằm trong các nghiên cứu về trí tuệ cảm xúc, cụ thể là quản lý cảm xúc và điều chỉnh cảm xúc. Một số nhà TLH có những đóng góp liên quan đến đề tài này được ghi nhận như Peter Salivey và John D. Mayer, Daniel Goleman, Petricdes và Furnham... Các tác giả Phạm Minh Hạc, Trần Trọng Thủy, Nguyễn Quang Uẩn, Nguyễn Huy Tú... cũng có một số công trình nghiên cứu về trí tuệ cảm xúc được công bố.

Khái niệm cảm xúc xuất phát từ thuật ngữ Latin "movere", nghĩa là "chuyển động" [5]. Đây là khái niệm phổ biến và đã được nhiều nhà Tâm lý học quan tâm. Trong đề tài này, chúng tôi đã tổng hợp các đặc điểm của cảm xúc và xác lập khái niệm công cụ như sau: "cảm xúc là nhũng rung động được biểu trung bằng các phản ứng sinh lý cũng như tâm lý của cá nhân đối với những sự vật, hiện tượng có liên quan đến nhu cầu và động co của cá nhân đó trong nhũng tình huống nhất định". Dựa vào việc cảm xúc có thỏa mãn nhu cầu của con người hay không, người ta chia cảm xúc thành hai loại là cảm xúc dương tính và CXÂT, trong đó, CXÂT là "những cảm xúc làm cho con người cảm thấy kó chịu, không thoải mái do nhu cầu của họ không được thỏa mãn" [3], [6].

Hoạt động nghề nghiệp của GVMN gắn liền với hoạt động giao tiếp giữa cô và trẻ. Trong đó, giao tiếp được hiểu là "hệ thống sụ tác động qua lại giũua GVMN và trẻ nhằm muc đích hiểu biết về trẻ; tổ chức các mối quan hẹ qua lại có muc đích giáo dục rõ ràng, hình thành bầu không khi thuận lợi cho sư phát triển của trẻ" [7]. Trong quá trình tác động qua lại này, yếu tố cảm xúc đóng vai trò rất quan trọng. Nếu các cảm xúc dương tính chiếm ưu thế, trường mầm non sẽ là một môi trường thân thiện, lớp học sẽ luôn vui tươi, trẻ em hạnh phúc khi đến trường. Ngược lại, nếu các CXÂT chiếm ưu thế, bản thân giáo viên sẽ mệt mỏi, mất dần hứng thú nghề nghiệp, trẻ sẽ không cảm thấy an toàn, sợ phải đến trường, hiệu quả giáo dục bị ảnh hưởng nghiêm trọng. Trong khi đó, các nghiên cứu gần đây về GVMN cho thây rằng, $G V M N$ đang phải chịu rất nhiều áp lực nghề nghiệp [8], công việc chăm sóc giáo dục trẻ vừa vất vả vừa có muôn vàn khó khăn là điều kiện thuận lợi cho các CXÂT nảy sinh, đòi hỏi người GVMN phải có kỹ năng điều chỉnh thích hợp.

Từ việc tham khảo các nghiên cứu của các tác giả trong và ngoài nước, trong phạm vi đề tài này, chúng tôi quan niệm "Kỹ năng điều chỉnh CXÂT trong giao tiếp với trẻ của GVMN là khả năng nhận ra nhũng CXÂT không phù hợp, tù đó lựa chọn và thực hiện các cách điều chỉnh hiệu quả nhằm giảm bớt hoạc thay đổi các CXÂT của bản thân giáo viên trong giao tiếp giũa họ với trẻ”.

Cấu trúc của kỹ năng điều chỉnh CXÂT trong giao tiếp với trẻ của GVMN bao gồm:

- Kỹ năng nhận ra các CXÂT không phù hợp với tình huống hiện tại, bao gồm khả năng phát hiện CXÂT của mình ngay khi nó vừa xuất hiện, khả năng nhận ra các dẩu hiệu của CXÂT, khả năng gọi chính xác tên của các CXÂT khi các cảm xúc ấy xuất hiện, khả năng đánh giá mức độ cảm xúc đang tồn tại và khả năng đánh giá mức độ phù hợp của CXÂT đang có.

- Kỹ năng thay đổi các CXÂT, bao gồm khả năng điều chỉnh mức độ CXÂT và khả năng điều hướng CXÂT thành cảm xúc dương tính.

\subsection{Kết quả nghiên cứu thực trạng}

Để tìm hiểu thực trạng kỹ năng điều chỉnh CXÂT trong giao tiếp với trẻ của GVMN, chúng tôi tiến hành khảo sát 254 GVMN tại 10 trường mầm non trên địa bàn Quận Tân Phú, Thành phố Hồ Chí Minh năm 2019, bao gồm cả trường công lập và ngoài công lập. Các phương pháp nghiên cứu được sử dụng bao gồm: 
phương pháp điều tra bằng bảng hỏi, phương pháp phỏng vấn, phương pháp quan sát và phương pháp thống kê toán học. Trong đó, phương pháp điều tra bàng bảng hỏi là phương pháp chính. Các câu hỏi tìm hiểu thời gian khách thể nhận ra sự xuất hiện của cảm xúc âm tính (bảng 1), việc xác định tên của cảm xúc đó và nhận thức của khách thể về các dấu hiệu của 5 cảm xúc âm tính với 10 dấu hiệu về cơ thể và hành vi tương ứng với 5 cảm xúc âm tính giận dữ, lo lắng, buồn, sợ hãi, chán nản (bảng 2). Chúng tôi không đưa các biểu hiện về mặt nhận thức của các cảm xúc trên đây vào khảo sát vì với các biểu hiện này, bản thân khách thể khi có cảm xúc âm tính sẽ rất khó nhận ra. Trong 22 tình huống với cách điều chỉnh cảm xúc có 19 tình huống đầu thể hiện các cách điều chỉnh mức độ cảm xúc âm tính theo tác giả Gross và Munoz đề nghị. Trong đó, các cách từ 1 đến 6 là cách điều chỉnh tập trung vào tình huống, các cách từ 7 đến 13 tập trung vào phản ứng đáp lại và các cách còn lại tập trung vào nhận thức. Các cách điều chỉnh thứ 20 và 21 là các cách điều hướng cảm xúc từ âm tính thành dương tính. Cách thứ 22 nhằm tìm hiểu mức độ không điều chỉnh cảm xúc âm tính trong giao tiếp với trẻ của GVMN (bảng 3). Việc xử lý số liệu được tính theo tỉ lệ \% và quy ước như sau:

\begin{tabular}{|l|c|c|}
\hline Mức độ & Điểm quy gán & ĐTB \\
\hline Không bao giờ & 1 & $1-1.8$ \\
\hline Hiếm khi & 2 & $1.9-2.6$ \\
\hline Thỉnh thoảng & 3 & $2.7-3.4$ \\
\hline Thường xuyên & 4 & $3.5-4.2$ \\
\hline Rất thường xuyên & 5 & $4.3-5.0$ \\
\hline
\end{tabular}

Nguồn: Số liệu phân tích dữ liệu nghiên cứu chính thức bằng SPSS 23.0 của tác giả

Trong phạm vi bài báo, chúng tôi chỉ khảo sát kỹ năng điều chỉnh 5 CXÂT là: giận dữ, lo lắng, buồn, sợ hãi và chán nản trong giao tiếp với trẻ của GVMN. Kết quả khảo sát thu được như sau:

\subsubsection{Kĩ năng nhận biết cảm xúc}

Trước hết, chúng tôi xem xét khả năng nhận diện các CXÂT khi các cảm xúc ấy vừa xuất hiện. Kết quả khảo sát về thời điểm nhận CXÂT trong giao tiếp với trẻ của GVMN như sau:

Bảng 1. Thời điểm nhận ra CXÂT của GVMN

\begin{tabular}{|l|l|l|}
\hline Thời điểm nhận ra CXẦT & Tần số & Tần suất \\
\hline Ngay khi CXÂT vừa xuất hiện & 139 & 54.7 \\
\hline Khi CXÂT đã khá mạnh & 73 & 28.7 \\
\hline Khi CXÂT đã rất mạnh mẽ & 17 & 6.7 \\
\hline Sau khi đã thực hiện hành vi theo sự thôi thúc của CXÂT & 25 & 9.8 \\
\hline
\end{tabular}

Nguồn: Số liệu phân tích dữ liệu nghiên cứu chính thức bằng SPSS 23.0 của tác giả

Việc nhận ra kịp thời sự xuất hiện của các CXÂT giúp GVMN nhanh chóng điều chỉnh được các cảm xúc này. Bảng 1 . cho thấy phần lớn GVMN cho rằng họ có thể nhận ra CXÂT ngay khi nó vừa xuất hiện. Tuy nhiên, tần suất các GVMN có độ nhạy kém trong việc nhận ra sự xuất hiện của các CXÂT vẫn khá cao, có đến $28.7 \%$ GVMN nhận ra CXẦT khi cảm xúc ấy đã khá mạnh và $6.7 \%$ nhận ra khi CXÂT đã rất mạnh mẽ. Rất đáng lưu ý là có đến $9.8 \%$ GVMN chỉ nhận ra CXÂT sau khi đã thực hiện các hành vi theo sự thôi thúc của CXÂT.

Việc gọi tên $C X A \hat{T}$ sau khi nhận ra sự xuất hiện của chúng có ý nghĩa quan trọng vì giúp GVMN chọn lựa được cách điều chỉnh phù hợp nhất. Kết quả khảo sát thể hiện ở bảng 2:

Bảng 2. Các mức độ nhận biết tên của CXÂT

\begin{tabular}{|l|l|l|}
\hline Các mức độ nhận biết tên của CXÂT & Tần số & Tần suất \\
\hline Có thể gọi chính xác tên của CXÂT & 115 & 45.3 \\
\hline Có ý niệm về tên của cảm xúc nhưng không chắc chắn & 77 & 30.3 \\
\hline Chỉ cảm thấy khó chịu, không rõ là cảm xúc gì & 41 & 16.1 \\
\hline Không chú ý đến CXÂT nên cũng không tìm cách gọi tên & 21 & 8.3 \\
\hline
\end{tabular}

Nguồn: Số liệu phân tích dữ liệu nghiên cứu chính thức bằng SPSS 23.0 của tác giả 
Bảng 2 cho thấy khá nhiều GVMN còn rất mơ hồ trong việc nhận diện tên các loại CXÂT. Thật đáng lo ngại khi mà trong các tình huống CXÂT xuất hiện, có đến $30.3 \%$ GVMN chỉ "có ý niệm về tên của cảm xúc nhưng không chắc chắn" và $16.1 \%$ GVMN "chỉ cảm thấy khó chịu, không rõ là cảm xúc gì”. Con số 8.3\% GVMN "không chú ý đến CXÂT nên cũng không tìm cách gọi tên" cũng rất đáng suy nghĩ vì cho thấy bộ phận giáo viên này chưa thực sự ý thức đủ về ảnh hưởng của CXÂT với bản thân và nghề nghiệp của mình, và cũng thể hiện một thực trạng chắc chắn là họ không hề chú ý đến việc điều chỉnh các cảm xúc này. Qua phỏng vấn, các giáo viên được hỏi đều cho rằng họ có để ý đến mức độ cảm xúc âm tính nơi họ, nhưng chủ yếu là "biết được lúc nào tôi không thể kiềm chế được nữa" (Cô Nh.).

Để đánh giá khả năng nhận diện các biểu hiện của CXÂT và khả năng gọi tên chính xác các cảm xúc này của GVMN, chúng tôi đưa ra 10 biểu hiện liên quan đến cơ thể và hành vi ứng với 5 cảm xúc đang khảo sát cho giáo viên nhận diện, kết quả cho thấy: đa số GVMN nhận ra các biểu hiện của cảm xúc giận dữ cả về mặt cơ thể $(66.9 \%)$ ) lẫn hành vi $(85.4 \%)$. Đối với cảm xúc lo lắng, phần lớn GVMN nhận ra các biểu hiện về mặt hành vi $(76.8 \%)$. Tuy nhiên, khi xem xét các biểu hiện về mặt cơ thể, chỉ có $31.9 \% \mathrm{GVMN}$ nhận diện đúng. Có đến $54.7 \%$ giáo viên nhầm lẫn các biểu hiện về mặt cơ thể của cảm xúc lo lắng là các dấu hiệu của cảm xúc sợ hãi. Ngoài ra, khi xem xét các cảm xúc buồn, sợ hãi và chán nản, việc GVMN nhận diện đúng các cảm xúc này ở mức rất thấp. Ngoài các biểu hiện về mặt cơ thể của cảm xúc sợ hãi các giáo viên nhận diện đúng được $52.8 \%$, ở các dấu hiệu khác của 3 cảm xúc này, mức độ nhận diện đúng đều dưới trung bình. Kết quả này khá phù hợp với việc tự đánh giá về khả năng gọi tên chính xác các CXÂT đã trình bày ở trên.

Khi được hỏi về khả năng xác định mức độ của CXÂT mà mình đang có trong quá trình giao tiếp với trẻ, điểm trung bình (ĐTB) các câu trả lời của giáo viên đạt 2.99 với độ lệch chuẩn (ĐLC) 1.039. Như vậy, khả năng xác định mức độ $\mathrm{CXÂT}$ của GVMN đạt ở mức "vừa phải" và có độ phân tán khá lớn. Khảo sát tần suất các lựa chọn cho kết quả, mức lựa chọn "vừa phải" là cao nhất, đạt $36.2 \%$. Trong khi đó, số giáo viên cảm thấy khả năng đánh giá mức độ cảm xúc của mình là "rất ít" và "ít" có tỉ lệ $33.1 \%$ cao hơn hẳn so với số giáo viên có khả năng này ở mức "nhiều" và "rất nhiều" chỉ đạt $30.7 \%$. Như vậy nhìn chung, khả năng đánh giá mức độ cảm xúc của GVMN trong giao tiếp với trẻ còn chưa cao.

Để đánh giá khả năng xác định phản úng cảm xúc phù hợp với hoàn cảnh của giáo viên, chúng tôi đưa ra một tình huống cụ thể, trong đó, giáo viên đang rất tức giận với trẻ cùng với 3 lựa chọn tương ứng với 3 mức độ phù hợp của cảm xúc là "trong tầm kiểm soát", "nguy hiểm", và "vượt tầm kiểm soát". Số giáo viên đã chọn được phản ứng cảm xúc phù hợp tương ứng với mức "trong tầm kiểm soát" là $53.9 \%$. Con số này chênh lệch không nhiều so với mức tự đánh giá của giáo viên ở trên. Vẫn còn $39.4 \%$ giáo viên đánh giá phản ứng cảm xúc "Cố gắng kiểm soát cảm xúc trong khi giải quyết mâu thuẫn ở góc xây dựng, luôn canh chùng để cảm xúc không bộc phát", tức mức độ cảm xúc "nguy hiểm", là phản ứng cảm xúc phù hợp. Đáng quan tâm hơn, có $6.7 \%$ giáo viên cho rằng họ "Không cần quan tâm đến cảm xúc của mình, đi thẳng đến góc xây dựng, yêu cầu trẻ gây sự trước xin lổi bạn và rời góc chơi đó” là phản ứng cảm xúc hợp lý, trong khi cách phản ứng này xét về mặt cảm xúc là ở mức "vượt tầm kiểm soát" vì để cảm xúc bộc lộ tự nhiên và chỉ hành động theo sự thôi thúc của cảm xúc.

Như vậy, đối với kỹ năng nhận ra các CXÂT không phù hợp với hoàn cảnh hiện tại, điểm tích cực là GVMN đã nhận ra sự xuất hiện của các CXÂT. Tuy nhiên, họ vẫn còn nhiều hạn chế trong việc nhận diện các biểu hiện và gọi tên chính xác từng CXÂT riêng lẻ cũng như khả năng xác định mức độ và tính phù hợp của CXÂT với tình huống chưa cao.

\subsubsection{Kỹ năng thay đổi các cảm xúc âm tính}

Đối với kỹ năng thay đổi các CXÂT, chúng tôi tìm hiểu thực trạng kỹ năng này thông qua việc đánh giá mức độ GVMN sử dụng 22 cách điều chỉnh cảm xúc cùng với các tình huống chúng tôi đưa ra. Kết quả thu được cho thấy hầu hết các GVMN đã sử dụng các biện pháp điều chỉnh CXÂT chúng tôi đưa ra ở mức "vừa phải”. Cụ thể: 
Bảng 3. Thực trạng sử dụng các cách điều chỉnh cảm xúc âm tính của GVMN

\begin{tabular}{|c|c|c|}
\hline Cách điều chỉnh cảm xúc không mong muốn & ĐТВ & ĐLC \\
\hline $\begin{array}{l}\text { 1. Tôi biết tình huống nào hay gây cảm xúc âm tính cho tôi và tôi hạn chế tham gia vào } \\
\text { tình huống đó nếu có thể. }\end{array}$ & 2.9 & 1.143 \\
\hline $\begin{array}{l}\text { 2. Tôi nhờ giáo viên đồng nghiệp quan tâm đến trẻ hay gây cảm xúc âm tính cho mình } \\
\text { và hạn chế giao tiếp với trẻ này. }\end{array}$ & 2.7 & 1.075 \\
\hline $\begin{array}{l}\text { 3. Tôi chủ động tham gia hoặc tạo ra các tình huống làm gia tăng cảm xúc dương tính } \\
\text { trong khi giao tiếp với trẻ. }\end{array}$ & 3.4 & 1.192 \\
\hline $\begin{array}{l}\text { 4. Tôi nhờ người khác hỗ trợ trong các tình huống tôi biết sẽ gây cảm xúc âm tính cho } \\
\text { tôi. }\end{array}$ & 2.7 & 1.066 \\
\hline $\begin{array}{l}\text { 5. Nếu trẻ không thích một món ăn, tôi cho trẻ ăn món đó ít lại và tăng cường món khác } \\
\text { để khỏi có cảm xúc âm tính vì trẻ ăn chậm. }\end{array}$ & 3.5 & 1.113 \\
\hline $\begin{array}{l}\text { 6. Trước khi tham gia vào tình huống tôi biết chắc sẽ gây cảm xúc âm tính cho tôi, tôi } \\
\text { nghĩ về các điều tích cực của tình huống đó. }\end{array}$ & 3.3 & 1.069 \\
\hline $\begin{array}{l}\text { 7. Tôi dành thời gian theo dõi các phản ứng cảm xúc hoặc viết ra các cảm xúc âm tính } \\
\text { của chính mình. }\end{array}$ & 2.4 & 0.994 \\
\hline 8. Tôi nói với trẻ về cảm xúc âm tính tôi đang có. & 2.4 & 1.129 \\
\hline $\begin{array}{l}\text { 9. Trao đồi với các đồng nghiệp về tình huống cảm xúc âm tính gặp phải để được thông } \\
\text { cảm, hỗ trơ và rút kinh nghiệm cho lần xử lý tiếp theo. }\end{array}$ & 3.1 & 1.050 \\
\hline $\begin{array}{l}\text { 10. Ngay khi nhận thức được cảm xúc âm tính, tôi tìm cách hướng suy nghĩ vào một } \\
\text { việc khác (nhìn trẻ khác, don dep bàn ghế...), để không bi cuốn theo cảm xúc ấy. }\end{array}$ & 3.4 & 1.068 \\
\hline $\begin{array}{l}\text { 11. Ngay sau khi tôi biết mình bị cuốn theo một cảm xúc âm tính mạnh, tôi điều chỉnh } \\
\text { bằng cách hít thở sâu hoăc uống } 1 \text { ngum nước. }\end{array}$ & 3.2 & 1.180 \\
\hline $\begin{array}{l}\text { 12. Ngay sau khi tôi biết mình có một cảm xúc âm tính mạnh, tôi cố kìm nén hoặc ngăn } \\
\text { chăn cảm xúc này cho khỏi ảnh hường đên công việc của tôi. }\end{array}$ & 3.3 & 1.025 \\
\hline $\begin{array}{l}\text { 13. Khi có cảm xúc âm tính, tôi tập trung vào làm thật nhiều việc để thoát khỏi cảm xúc } \\
\text { này. }\end{array}$ & 3.2 & 1.053 \\
\hline $\begin{array}{l}\text { 14. Tôi nghĩ cảm xúc âm tính là điều đương nhiên phải có và không lên án mình vì có } \\
\text { những cảm xúc ây. }\end{array}$ & 3.4 & 1.068 \\
\hline $\begin{array}{l}\text { 15. Khi gặp sự kiện gây cảm xúc âm tính, tôi nghĩ đến khía cạnh tích cực của sự kiện } \\
\text { này. }\end{array}$ & 3.4 & 1.013 \\
\hline $\begin{array}{l}\text { 16. Khi gặp sự kiện gây cảm xúc âm tính, tôi nhớ đến các trải nghiệm tích cực tôi đã có } \\
\text { trước đây trong các hoàn cảnh tương tư để thav đổi cảm xúc. }\end{array}$ & 3.4 & 1.030 \\
\hline $\begin{array}{l}\text { 17. Tôi tập trung vào việc suy nghĩ để giải quyết sự kiện gây ra cảm xúc âm tính hơn là } \\
\text { chú tâm vào cảm xúc âm tính đang có. }\end{array}$ & 3.3 & 0.949 \\
\hline 18. Tôi học cách xử lý cảm xúc thay vì trừng phạt người gây ra cảm xúc. & 3.3 & 0.990 \\
\hline $\begin{array}{l}\text { 19. Tôi tự đặt mình vào tình huống của trẻ gây ra cảm xúc âm tính cho tôi để thông cảm } \\
\text { với trẻ hơn. }\end{array}$ & 3.5 & 0.960 \\
\hline $\begin{array}{l}\text { 20. Tôi nghĩ đến khía cạnh tức cười, hài hước của tình huống gây cảm xúc âm tính để } \\
\text { thay đổi cảm xúc. }\end{array}$ & 3.2 & 1.092 \\
\hline $\begin{array}{l}\text { 21. Tôi coi việc vượt qua các cảm xúc âm tính là một thử thách và việc vượt qua nó đem } \\
\text { lại niềm vui trong công việc của tôi. }\end{array}$ & 3.3 & 1.038 \\
\hline $\begin{array}{l}\text { 22. Tôi để cho các cảm xúc âm tính trong giao tiếp với trẻ mất đi một cách tự nhiên bằng } \\
\text { cách không quan tâm đến nó. }\end{array}$ & 3.1 & 1.086 \\
\hline
\end{tabular}

Nguồn: Số liệu phân tích dữ liệu nghiên cứu chính thức bằng SPSS 23.0 của tác giả

Với 19 cách đầu tiên, chúng tôi tìm hiểu khả năng điều chỉnh mức độ CXÂT. Kết quả chỉ có 2 cách được GVMN sử dụng "thường xuyên" với ĐTB = 3.5 là cách 5: "Nếu trẻ không thích một món ăn, tôi cho trẻ ăn món đó it lại và tăng cuờng món khác để khỏi có CXÂT vì trẻ ăn chậm" (ĐLC=1.113). Đây là cách điều chỉnh tập trung vào tình huống gây CXÂ. Cách 19: "Tôi tụ đặt mình vào tình huống của trẻ gây ra CXÂT cho tôi để thông cảm với trẻ hơn" ( $\mathrm{ĐLC}=0.960)$. Cách điều chỉnh này tập trung vào nhận thức của 
giáo viên. Đây là cách điều chỉnh cảm xúc mang lại hiệu quả cao vì khi đặt mình vào tình huống của trẻ, GVMN đã tạm thời di chuyển sự chú ý ra khỏi bản thân với các nhu cầu không được thỏa mãn của mình (nguyên nhân gây CXÂT). Đồng thời, việc đặt mình vào tình huống của trẻ giúp giáo viên hiểu về trẻ nhiều hơn, thông cảm với trẻ hơn. Các cách điều chỉnh CXÂT còn lại GVMN chỉ sử dụng ở mức "vừa phải”. Tổng hợp các cách điều chỉnh CXÂT của GVMN theo các nhóm điều chỉnh tập trung vào tình huống, tập trung vào phản ứng đáp lại và tập trung vào nhận thức, kết quả cho thấy GVMN sử dụng cách điều chỉnh CXẦT tập trung vào nhận thức nhiều hơn các cách điều chỉnh cảm xúc khác. Đây là cách điều chỉnh rất được các nhà tâm lý học khuyến khích. Có thể nói, các GVMN đang đi đúng hướng trong quá trình rèn luyện kỹ năng điều chỉnh CXÂT của mình.

Đối với khả năng điều hướng CXÂT thành cảm xúc duơng tính, các cách điều hướng cảm xúc chủ yếu dựa vào kỹ thuật tập trung vào nhận thức và khảo sát với 2 cách số 20 và 21 trong bảng hỏi. ĐTB thu được là 3.2 với cách điểu chỉnh 20: "Tôi nghĩ đến khía cạnh tức cười, hài hước của tình huống gây CXÂT để thay đổi cảm xúc" và ĐTB là 3.3 với cách điều chỉnh 21: "Tôi coi việc vượt qua các CXÂT là một thư thách và việc vượt qua nó đem lại niềm vui trong công việc của tôi”. Quan sát mức độ sử dụng của cả 2 cách cho thấy chỉ có chưa tới $1 / 3$ số GVMN áp dụng các cách điều chỉnh cảm xúc này ở mức "thường xuyên" đến "rất thường xuyên" mà thôi. Như vậy, GVMN tự nhận xét mình đã sử dụng các cách điều chỉnh cảm xúc này ở mức "vừa phải”. Điều đó cho thấy mức độ kỹ năng đạt được kỹ năng thay đổi các CXÂT của các giáo viên hiện nay là chưa cao.

\subsection{Biện pháp rèn luyện kỹ năng điều chỉnh $\mathrm{CXÂT}$}

Nhằm giúp GVMN nâng cao kỹ năng điều chỉnh CXÂT trong giao tiếp với trẻ, chúng tôi đề xuất một số biện pháp rèn luyện kỹ năng này. Các biện pháp được đề xuất đã qua khảo sát về mức độ cần thiết và mức độ khả thi. Kết quả cho thấy các GVMN đánh giá cao các biện pháp chúng tôi đưa ra, phần lớn các ý kiến được khảo sát đều tập trung ở mức "cần thiết" và "khả thi". Các biện pháp bao gồm:

Biện pháp 1: Trang bị tri thức cho GVMN về kỹ năng điều chỉnh CXÂT trong giao tiếp với trẻ Mục tiêu của biện pháp

Biện pháp này giúp GVMN được trang bị hệ thống tri thức liên quan đến kỹ năng điều chỉnh CXÂT trong giao tiếp với trẻ một cách đầy đủ, chính xác. Từ đó, họ có cơ sở để rèn luyện kỹ năng này.

Nội dung của biện pháp

- Trang bị kiến thức về các CXÂT như: khái niệm, nguyên nhân, biểu hiện, các mức độ, vai trò, quy luật hình thành và phát triển... của các CXÂT, cách thức phân biệt các CXÂT, sự pha trộn các CXÂT.

- Trang bị kiến thức về kỹ năng điều chỉnh CXÂT, đặc biệt là các cách thức điều chỉnh cảm xúc.

- Trang bị kiến thức về các yếu tố ảnh hưởng đến kỹ năng điều chỉnh CXÂT trong giao tiếp với trẻ.

Một điều quan trọng nữa là trang bị các kiến thức về tâm lý trẻ. Nhiều khi giáo viên có CXÂT là do chưa hiểu hết tâm lý trẻ, ứng xử với trẻ như là với người lớn. Khi trẻ không đáp ứng được mong đợi của giáo viên, họ lại tự đưa mình vào CXÂT ở mức không cần thiết.

Cách tiến hành

- Tổ chức giảng dạy về kỹ năng điều chỉnh CXÂT trong trường sư phạm và tập huấn tại các cơ sở giáo dục mầm non.

- Tăng cường các thông tin về CXÂT và cách điều chỉnh các cảm xúc này trên các phương tiện thông tin đại chúng như đài, ti vi, sách báo, mạng xã hội...

- Trang bị các tờ rơi, sách giới thiệu về cảm xúc, xây dựng cẩm nang và bài tập thực hành kỹ năng điều chỉnh CXÂT dành cho giáo viên.

Biện pháp 2: Hướng dẫn GVMN rèn luyện kỹ năng nhận ra các CXÂT không phù hợp với hoàn cảnh hiện tại

Mục tiêu của biện pháp

Biện pháp này giúp GVMN quan tâm và nhạy cảm với các cảm xúc của bản thân, từ đó nhanh chóng nhận ra các CXÂT không phù hợp với hoàn cảnh để có thể điều chỉnh kịp thời.

Nội dung của biện pháp 
- Rèn luyện kỹ năng nhận diện các CXÂT ngay khi nó vừa xuất hiện, biết được các biểu hiện và gọi được chính xác tên của cảm xúc ấy.

- Rèn luyện kỹ năng đánh giá mức độ của cảm xúc đang có, từ đó biết được cảm xúc đó có phù hợp với hoàn cảnh hay không.

Cách tiến hành

Tổ chức các lớp tập huấn theo nhóm nhỏ với các phương pháp thảo luận, trò chơi, đóng vai, phân tích các biểu hiện và các mức độ cảm xúc qua phim ảnh, thực hành các bài tập xác định $\mathrm{CXÂT}$, ghi nhật ký cảm xúc.

Biện pháp 3: Hướng dẫn GVMN rèn luyện kỹ năng thay đổi các CXÂT

Mục tiêu của biện pháp

Biện pháp này giúp GVMN thay đổi các $\mathrm{CXÂT}$ không phù hợp với hoàn cảnh thành các cảm xúc có sự phù hợp hơn hoặc tạo ra các cảm xúc tối ưu trong quá trình giao tiếp nhằm thực hiện mục tiêu giáo dục trẻ.

Nội dung của biện pháp

- Hướng dẫn giáo viên hiểu rõ ưu, nhược của các cách điều chỉnh cảm xúc, biết lựa chọn các cách điều chỉnh phù hợp với từng loại $\mathrm{CXÂT}$ và trong từng tình huống cụ thể.

- Rèn luyện khả năng điều chỉnh mức độ $\mathrm{CXÂT}$, bao gồm việc giảm cường độ một $\mathrm{CXÂT}$ đang có sao cho nó ở trong tầm kiểm soát hoặc khơi lên một CXÂT để đạt được mục đích giáo dục cho trẻ.

- Rèn luyện khả năng điều hướng CXÂT thành cảm xúc dương tính.

Cách tiến hành

Tổ chức các lớp tập huấn với các nhóm nhỏ, sử dụng phương pháp thảo luận, các bài tập thực hành về các cách thức và các liệu pháp điều chỉnh cảm xúc.

Biện pháp 4: Hướng dẫn GVMN đánh giá và hiệu chỉnh kỹ năng điều chỉnh CXÂT trong giao tiếp với trẻ Mục tiêu của biện pháp

Biện pháp này nhằm giúp GVMN thường xuyên đánh giá kỹ năng điều chỉnh CXÂT của bản thân, từ đó có những hiệu chỉnh phù hợp để ngày càng nâng cao kỹ năng này hơn.

Nội dung của biện pháp

- Đánh giá mức độ đạt được kỹ năng điều chỉnh CXÂT trong giao tiếp với trẻ của GVMN dựa trên các tiêu chí đánh giá kỹ năng.

- Hiệu chỉnh kỹ năng cho phù hợp với sự thay đổi của hoàn cảnh.

Cách tiến hành

- Tổ chức các lớp chuyên đề, tập huấn nhằm cung cấp cho giáo viên các chuẩn để đánh giá kỹ năng.

- Bản thân GVMN tự đánh giá kỹ năng theo các chuẩn đã được cung cấp. Sau khi tự đánh giá, so sánh với mục tiêu hình thành kỹ năng và các cách thức điều chỉnh cảm xúc để có hiệu chỉnh thích hợp.

- Đối với các GVMN gặp khó khăn với việc thực hành kỹ năng, tổ chức các lớp tập huấn theo nhóm nhỏ, hoặc cá nhân gặp gỡ các chuyên viên tâm lý, phân tích nhật ký cảm xúc để có hiệu chỉnh thích hợp nhờ sự hướng dẫn của giảng viên hay chuyên viên tâm lý.

\section{KẾT LUẬN}

Kỹ năng điều chỉnh CXÂT trong giao tiếp với trẻ của GVMN là một trong những kỹ năng rất quan trọng, có ảnh hưởng lớn tới chất lượng chăm sóc, giáo dục trẻ tại trường mầm non. Tuy nhiên, kết quả khảo sát thực trạng cho thấy còn nhiều giáo viên chưa quan tâm đến việc điều chỉnh CXÂT. Phần lớn GVMN đã nhận diện được sự xuất hiện của CXÂT nhưng việc gọi tên chính xác cũng như việc nhận diện các biểu hiện của CXẦT còn nhiều hạn chế. Khả năng đánh giá mức độ $C X A \hat{T}$ của GVMN còn chưa cao và vẫn còn nhiều giáo viên chưa xác định đúng mức độ cảm xúc phù hợp với hoàn cảnh. Hầu hết các GVMN đã biết một số cách điều chỉnh CXÂT nhưng chỉ sử dụng ở mức vừa phải, trong đó, nhóm các biện pháp tập trung vào nhận thức được sử dụng nhiều nhất. Thực trạng trên cho thấy, GVMN chỉ có kỹ năng điều chỉnh CXÂT ở mức trung bình. Để có thể nâng cao chất lượng chăm sóc, giáo dục trẻ, GVMN rất cần rèn luyện thêm kỹ năng này. Chúng tôi đã gợi ý một số biện pháp hỗ trợ các giáo viên rèn luyện kỹ năng. Nếu các biện pháp 
này được áp dụng cùng với sự nỗ lực không ngừng của các GVMN thì khẩu hiệu "vì một ngôi trường hạnh phúc" chắc hẳn sẽ được thực hiện.

\section{TÀI LIỆU THAM KHẢO}

[1] Vũ Dũng (chủ biên) (2000), Tư điển tâm lý học, NXB Khoa Học Xã Hội.

[2] Hoàng Phê (chủ biên) (2003), Tù điển Tiếng Việt, NXB Đà Nẵng.

[3] Huỳnh Văn Sơn, Lê Thị Hân (Chủ biên), 2018, Trần Thị Thu Mai, and Nguyễn Thị Uyên Thy, Giáo trình Tâm lý học đại cuoong. NXB Đại Học Sư Phạm Tp.HCM.

[4] Quốc Hội Nước Cộng Hòa Xã Hội Chủ Nghĩa Việt Nam, Luật Giáo dục. NXB Chính trị Quốc gia Hà Nội.

[5] Đặng Phương Kiệt, 2001,Co sở tâm lý học ứng dụng, tập 1. NXB Đại Học Quốc Gia Hà Nội.

[6] Đinh Thị Hồng Vân, 2014, Cách ứng phó với CXÂT trong quan hệ xã hội của trẻ vị thành niên Thành phố Huế. Luận án Tiến sĩ Tâm lý học, Học viện Khoa học Xã hội, 2014.

[7] Lê Xuân Hồng,2004, Một số vấn đề về giao tiếp và giao tiếp su phạm trong hoạt động của giáo viên mầm non. NXB Giáo Dục.

[8] Trịnh Viết Then, 2016, Stress ở giáo viên mầm non. Luận án Tiến sĩ Tâm lý học, Học viện Khoa học Xã hội.

Ngày nhận bài: 28/04/2020

Ngày chấp nhận đăng: 10/12/2020

CC 2020 Trường Đại học Công nghiệp Thành phố Hồ Chí Minh 